\title{
Matrix effect of aluminium, calcium and magnesium in axially viewing inductively coupled plasma atomic emission spectrometry
}

\author{
María T. Larrea, ${ }^{a}$ Bryan Zaldívar, ${ }^{b}$ Juan C. Fariñas, ${ }^{c}$ Laura G. Firgaira ${ }^{d}$ and \\ Mario Pomares $* b$
}

Received 20th June 2007, Accepted 31st August 2007

First published as an Advance Article on the web 17th September 2007

DOI: $10.1039 / \mathbf{b} 709359 d$

The matrix effect due to $\mathrm{Al}, \mathrm{Ca}$ and $\mathrm{Mg}$ in axial view mode ICP-AES was investigated over analyte lines with total excitation energy from 1.62 to $16.51 \mathrm{eV}$. A global qualitative explanation of the action of the matrix is proposed. The energy is directly transferred between matrix and analyte specimens (atoms or ions) during inelastic collisions, which are particularly relevant in the $1.62-8 \mathrm{eV}$ excitation energy range, where the direct action with argon specimens is less probable to occur. Concrete applications of this global qualitative explanation are given, taking into account the resonance energy effect and the spin conservation rule. The characteristic matrix effect of $\mathrm{Al}$ and $\mathrm{Ca}$ for lines excited by charge transference mechanism was observed. In the presence of $\mathrm{Mg}$, other possible matrix-analyte interactions may reduce the efficiency of this mechanism. The particular behavior of the matrix effect for lines in the 10.5-11.5 eV energy range can be considered as experimental evidence of the Penning ionization-excitation mechanism, which probably actuates along other matrix-analyte interactions.

\section{Introduction}

Inductively coupled plasma atomic emission spectrometry (ICP-AES) is a well-established analytical technique. ${ }^{1}$ Nevertheless, the matrix effect (ME) is probably one of the most crucial limitations leading to a possible deterioration of the accuracy of analysis. $^{2}$

A considerable number of reports ${ }^{3-5}$ has been dedicated to the study of the ME. They agree in the fact that MEs depend on the operating conditions of the ICP system, the types and concentrations of major elements and the total excitation energy (TEE) of analytes. The TEE is the excitation energy for the atomic lines or the sum of the excitation energy of the line plus the ionization energy of the atom for ionic lines.

The ME is significantly reduced for radial and axial view modes at "robust conditions". ${ }^{6-8}$ However, in these conditions the analyte signals are still affected by the matrix. $^{6-17}$

The relationship between ME and TEE is rather complex. ${ }^{9,10,14}$ For radial view mode ICPs at "typical operating parameters", the relatively lower effect (enhancement and depression) over atomic lines and the increase of the depressive effect of $\mathrm{Ca}$ with the increase of TEE of ionic lines have been reported. ${ }^{13,18,19}$

\footnotetext{
${ }^{a}$ Centro Nacional de Investigaciones Metalúrgicas (CSIC), 28040 Madrid, España

${ }^{b}$ Instituto de Ciencia y Tecnología de Materiales, Universidad de la Habana, 10400 La Habana, Cuba.E-mail: mpomares@imre.oc.uh.cu ${ }^{c}$ Instituto de Cerámica y Vidrio (CSIC), Campus de Cantoblanco, 28049 Madrid, España

${ }^{d}$ Centro de Espectrometría Atómica, Universidad Complutense de Madrid, 28040 Madrid, España
}

For axial view mode, MEs also behave in a complex manner. Under robust conditions, the intensity of lines with higher $(\approx 15.19 \mathrm{eV})$ TEE was more depressed by $\mathrm{Ca}$ and $\mathrm{Na}$ than lines with lower TEE $(\approx 1.85 \mathrm{eV}) .{ }^{11}$ While, under near robust conditions, the effect of $\mathrm{Ca}$ was larger for lines in both extremes of the TEE range $(1.85-16.50 \mathrm{eV})$ and ME was not correlated with TEE for many lines. ${ }^{12}$ This lack of correlation was also reported under non-robust and robust conditions in axial view mode. ${ }^{10,14}$ On the contrary, the linear relationship between ME and TEE was demonstrated for $\mathrm{Ca}$ and $\mathrm{Na}$ matrices in robust axially and radially viewed ICPs. ${ }^{13}$ Atomic lines with low TEE were explicitly excluded ${ }^{14}$ or not considered in other reports. ${ }^{13,15,16}$

It is well documented that there is an absence of a unique theory to explain the ME in ICP-AES, where many mechanisms have been proposed. ${ }^{5,20,21}$ Most of the proposed mechanisms should be supported for an increment in the electron number density $\left(N_{\mathrm{e}}\right)$ due to the matrix. However, the ME has been also observed for difficult-to-ionize matrices. ${ }^{22}$ Scarce information is given about ME mechanisms in axially viewed plasmas. In contrast, the more recent propositions $s^{7,8,10,17}$ have been reported in radial view mode. The proposed mechanisms do not explain the simultaneous enhancement and suppression of intensity lines observed high in the radial $^{7,8}$ but not in the axial view plasma. ${ }^{10,14}$

The main aim of the present work is to study the matrix effect of $\mathrm{Al}, \mathrm{Ca}$ and $\mathrm{Mg}$, major elements present in a great variety of natural samples, at both robust and non-robust conditions in axial view mode ICP system. A global qualitative explanation for the action of the studied matrices over the entire total excitation energy range of $1.62-16.51 \mathrm{eV}$ of the lines will be presented. 
Table 1 Operating conditions for Optima 3300 DV ICP optical emission spectrometer

\begin{tabular}{ll}
\hline Parameter & Value \\
\hline Plasma viewing mode & Axial \\
Read time/s & 2 \\
Measurement replicates & 4 \\
Generator frequency $/ \mathrm{MHz}$ & 40 \\
$\begin{array}{l}\text { Incident power } / \mathrm{kW} \\
\quad \text { robust } / \text { non-robust conditions }\end{array}$ & $1.5 / 0.8$ \\
Plasma argon flow rate $/ 1 \mathrm{~min}^{-1}$ & 15 \\
Nebulizer argon flow rate $/ 1 \mathrm{~min}^{-1}$ & \\
$\quad$ robust/non-robust conditions & $0.6 / 1.20$ \\
Auxiliary argon flow rate $/ \mathrm{min}^{-1}$ & 1 \\
Sample uptake rate $/ \mathrm{ml} \mathrm{min}$ & -1 \\
Inner diameter of the torch injector/mm & 1 \\
Nebulizer type & 2.0 \\
Spray chamber type & Perkin-Elmer cross-flow \\
\hline
\end{tabular}

\section{Experimental}

\section{Instrumentation}

A Perkin-Elmer (Norwalk, CT, USA) Optima 3300 DV ICP system was used at plasma operating conditions shown in Table 1.

\section{Reagents}

Solutions were prepared by dilution of $10000 \mathrm{mg}^{-1}$ unielemental or $1000 \mathrm{mg}^{-1}$ multielemental CertiPUR ${ }^{\circledR}$ grade (Merck, Darmstadt, Germany) standards solutions, except for $\mathrm{P}$, where $1000 \mathrm{mg} \mathrm{l}^{-1}$ Pure grade (Inorganic Ventures, Iv Labs, USA) standard solution was employed. Suprapur-grade (Merck) 65\% nitric acid was used. De-ionized water with a resistivity of $>18 \mathrm{M} \Omega \mathrm{cm}$, produced by a Milli-Q Plus system from Millipore (Bedford, MA, USA), was employed for all preparations of the standards.

\section{Test solutions}

Four types of solutions were prepared in order to study the ME. The type 1 solutions contained $1000 \mathrm{mg}^{-1}$ of the $\mathrm{Al}, \mathrm{Ca}$, or $\mathrm{Mg}$ matrix together with $10 \mathrm{mg} \mathrm{l}^{-1}$ of each analyte (Al, B, $\mathrm{Bi}, \mathrm{Ba}, \mathrm{Ca}, \mathrm{Cd}, \mathrm{Co}, \mathrm{Cr}, \mathrm{Cu}, \mathrm{Fe}, \mathrm{K}, \mathrm{Li}, \mathrm{Mg}, \mathrm{Mn}, \mathrm{Na}, \mathrm{Ni}, \mathrm{P}, \mathrm{Pb}$, $\mathrm{Sr}, \mathrm{Ti}, \mathrm{V}$ and $\mathrm{Zn}$ ). The type 2 solutions were the respective matrix blanks of type 1 solutions. The type 3 solution contained only $10 \mathrm{mg} \mathrm{l}^{-1}$ of each analyte and the type 4 solution was the blank solution. All the solutions were $5 \%(\mathrm{v} / \mathrm{v})$ in nitric acid.

\section{Results and discussion}

The ME, expressed as percent, was calculated for analyte lines, free from spectral interferences, in Table 2 by eqn 1 :

$$
\mathrm{ME}=\left[\left(\frac{I_{1}-I_{2}}{I_{3}-I_{4}}\right)-1\right] \times 100
$$

$I_{x}(x=1,2,3$ and 4$)$ is the net intensity measured for each line in the four kinds of solutions described. The solutions were continuously monitored to reduce any deviations due to possible temporal drifts. Eight ME replicates were averaged for each analyte. Precision in ME determination was $10 \%$ or better.
The $\mathrm{Mg}$ II $280.270 \mathrm{~nm} / \mathrm{Mg}$ I $285.213 \mathrm{~nm}$ ratio $(\mathrm{Mg} \mathrm{II} / \mathrm{Mg} \mathrm{I})^{6}$ was used to determine the robust $(P=1.5 \mathrm{~kW}, \Phi=0.61$ $\left.\min ^{-1}\right)$ and non-robust $\left(P=0.80 \mathrm{~kW}, \Phi=1.201 \mathrm{~min}^{-1}\right)$ plasma conditions. $\mathrm{Mg} \mathrm{II} / \mathrm{Mg}$ I was 11.65 and 0.36 , respectively. The ME due to $\mathrm{Al}, \mathrm{Ca}$ and $\mathrm{Mg}$ will be evaluated at both robust and non-robust conditions for comparison.

To test whether a linear relationship exists ${ }^{23}$ between ME (y) and TEE $(x)$, the null hypothesis $\left(H_{0}: \rho_{x y}=0\right)$ is that in the whole population there is no linear relationship between " $y$ " and " $x$ ", versus $H_{\mathrm{a}}: \rho_{x y} \neq 0$. The rejection rule is: reject $H_{0}$ if $\left|t_{\mathrm{e}}\right|>t_{\alpha / 2}$; otherwise, do not reject $H_{0} . t_{\mathrm{e}}$ ( $t$ experimental) is calculated by the equation $t_{\mathrm{e}}=R \times \sqrt{\frac{n-2}{1-R^{2}}}$ where $n$ is the number of (TEE, ME) pairs and $R$ is the correlation coefficient. $t_{\alpha / 2}$ is selected from the table of $t$-student distribution for $n-2$ degrees of freedom and confidence level $(\alpha)$ of 0.05 .

\section{Matrix effect under non-robust conditions}

The linear relationship between $\mathrm{ME}$ and TEE is statistically significant, with $R$ of $-0.72,-0.71$ and -0.69 for $\mathrm{Al}, \mathrm{Ca}$ and $\mathrm{Mg}$, respectively (Fig. 1). The fluctuations of $\mathrm{ME}$ from the tendency lines increase for the extremes of the energy range. Furthermore, ME is larger for lines with lower TEE.

The intersection point ( $\mathrm{TEE}_{\mathrm{i}}$ for short) of the tendency line with the abscissa axis defines two groups of lines: atomic and ionic lines with TEE $<\mathrm{TEE}_{\mathrm{i}}$, for which $\mathrm{ME}>0$ or $\mathrm{ME}<0$ and ionic lines with $\mathrm{TEE}>\mathrm{TEE}_{\mathrm{i}}$, for which $\mathrm{ME}<0$. As exceptions, $\mathrm{ME} \sim 0$ for some lines in both groups. $\mathrm{TEE}_{\mathrm{i}}$ is $7.50 \mathrm{eV}$ for $\mathrm{Al}$ and $\mathrm{Ca}$ matrices and $8.50 \mathrm{eV}$ for $\mathrm{Mg}$. An intermediate TEE $=8 \mathrm{eV}$ is selected for a more exhaustive study of the ME.

The ME-TEE relationship remains statistically significant for lines with TEE $<8 \mathrm{eV}$. $R$ was between -0.66 and -0.71 , similar to that calculated for the complete energy range. However, the slope of the tendency line increased between -8.3 and -7.2 .

The ME behaves in a more complex manner for lines with $\mathrm{TEE} \approx 8-16.51 \mathrm{eV}$. The ME-TEE linear relationship is not statistically significant for Ca $(R=-0.22$ in Fig. $2 b)$ nor for $\operatorname{Mg}(R=-0.29$ in Fig. 2c), while correlation decreased for the Al matrix $(R=-0.47$ in Fig. $2 \mathrm{a})$.

The depressive MEs due to $\mathrm{Al}, \mathrm{Ca}$ and $\mathrm{Mg}$ firstly increase in the TEE ranges of $8-14 \mathrm{eV}, 8-12 \mathrm{eV}$ and $8-13 \mathrm{eV}$, respectively (Fig. 2a-c). Thereafter, MEs of $\mathrm{Al}$ and $\mathrm{Ca}$ decrease with the increasing TEE. This change of the slope of the general tendency of $\mathrm{Al}$ and $\mathrm{Ca}$ MEs can be considered as experimental evidence of the charge transference excitation mechanism of analytes in axial view mode ICP. This characteristic ME was previously observed in radial view mode ICPs. ${ }^{8,24,25}$ In contrast, the $\mathrm{Mg}$ effect is almost negligible for most of the lines with TEE $\approx 13.5-14.5 \mathrm{eV}$, and does not diminish for lines with TEE $>13 \mathrm{eV}$. This differentiated behavior of the $\mathrm{Mg}$ effect requires more experiments, beyond the scope of the present work, to be elucidated.

The specific behavior of the lines with TEE between 10.5 and $11.5 \mathrm{eV}$, visualized by the dotted rectangles in Fig. $2 \mathrm{a}-\mathrm{c}$, deserves special attention. It will be discussed in the matrixanalyte interaction for TEE $>8 \mathrm{eV}$ section. 
Table 2 Emission lines studied with the corresponding excitation energy for atomic (I) and total excitation energy (excitation plus ionization energy) for the ionic (II) lines

\begin{tabular}{|c|c|c|c|c|c|}
\hline Element & Energy/eV & Element & Energy/eV & Element & Energy/eV \\
\hline $\mathrm{K}(\mathrm{I}) 766.490$ & 1.62 & $\mathrm{Li}(\mathrm{I}) 413.256$ & 4.85 & P(I) 213.617 & 7.21 \\
\hline $\mathrm{Na}(\mathrm{I}) 589.592$ & 2.10 & B(I) 249.677 & 4.96 & $\mathrm{Cd}(\mathrm{I}) 361.051$ & 7.38 \\
\hline $\mathrm{Na}(\mathrm{I}) 588.995$ & 2.11 & B(I) 249.772 & 4.96 & $\mathrm{Ba}$ (II) 493.408 & 7.72 \\
\hline $\operatorname{Sr}(\mathrm{I}) 460.733$ & 2.69 & $\mathrm{Al}(\mathrm{I}) 237.313$ & 5.24 & $\mathrm{Zn}(\mathrm{I}) 330.258$ & 7.78 \\
\hline $\mathrm{K}$ (I) 404.721 & 3.06 & $\mathrm{Ni}(\mathrm{I}) 232.003$ & 5.34 & $\mathrm{Zn}(\mathrm{I}) 334.501$ & 7.78 \\
\hline $\mathrm{Al}(\mathrm{I}) 396.153$ & 3.14 & $\operatorname{Mg}(\mathrm{I}) 285.213$ & 5.35 & $\mathrm{Ba}$ (II) 455.403 & 7.93 \\
\hline $\mathrm{Al}(\mathrm{I}) 394.401$ & 3.14 & $\mathrm{Cd}(\mathrm{I}) 228.802$ & 5.42 & $\mathrm{Sr}(\mathrm{II}) 421.552$ & 8.63 \\
\hline $\mathrm{Cr}(\mathrm{I}) 357.869$ & 3.46 & $\mathrm{Bi}(\mathrm{I}) 223.061$ & 5.56 & $\operatorname{Sr}(\mathrm{II}) 407.771$ & 8.73 \\
\hline $\mathrm{Ni}(\mathrm{I}) 341.476$ & 3.65 & Bi(I) 222.821 & 5.56 & $\mathrm{Ca}(\mathrm{II}) 396.847$ & 9.24 \\
\hline $\mathrm{Na}$ (I) 330.237 & 3.75 & $\mathrm{Cu}(\mathrm{I}) 222.778$ & 5.57 & $\mathrm{Ca}(\mathrm{II}) 393.366$ & 9.26 \\
\hline $\mathrm{Cu}(\mathrm{I}) 327.393$ & 3.79 & $\mathrm{~Pb}(\mathrm{I}) 261.418$ & 5.71 & Ti(II) 337.279 & 10.52 \\
\hline $\mathrm{Cu}(\mathrm{I}) 324.752$ & 3.82 & $\mathrm{~Pb}(\mathrm{I}) 217.000$ & 5.71 & Ti(II) 336.121 & 10.55 \\
\hline $\mathrm{Li}(\mathrm{I}) 610.362$ & 3.88 & $\mathrm{Zn}(\mathrm{I}) 213.857$ & 5.80 & Ti(II) 334.940 & 10.58 \\
\hline $\mathrm{Ca}(\mathrm{I}) 422.673$ & 3.93 & $\mathrm{~B}(\mathrm{I}) 208.957$ & 5.93 & $\mathrm{Ti}(\mathrm{II}) 368.519$ & 10.77 \\
\hline $\mathrm{Al}(\mathrm{I}) 308.215$ & 4.02 & B(I) 208.889 & 5.93 & $\mathrm{Ba}(\mathrm{II}) 413.065$ & 10.93 \\
\hline $\mathrm{Al}(\mathrm{I}) 309.271$ & 4.02 & $\mathrm{Bi}(\mathrm{I}) 206.170$ & 6.01 & V(II) 311.071 & 11.08 \\
\hline $\mathrm{Bi}(\mathrm{I}) 306.766$ & 4.04 & $\mathrm{~Pb}(\mathrm{I}) 224.688$ & 6.66 & V(II) 310.230 & 11.11 \\
\hline $\mathrm{Pb}(\mathrm{I}) 283.306$ & 4.37 & $\mathrm{~B}(\mathrm{I}) 182.528$ & 6.79 & Ti(II) 334.903 & 11.14 \\
\hline $\mathrm{Li}(\mathrm{I}) 460.286$ & 4.54 & P(I) 214.914 & 7.18 & V(II) 309.310 & 11.15 \\
\hline $\mathrm{Ba}$ (II) 230.425 & 11.19 & Mn(II) 293.305 & 12.83 & Sr(II) 232.235 & 14.06 \\
\hline $\mathrm{Ba}$ (II) 233.527 & 11.22 & $\mathrm{Cr}(\mathrm{II}) 267.716$ & 12.95 & Ni(II) 227.022 & 14.26 \\
\hline V(II) 292.402 & 11.38 & $\mathrm{Fe}(\mathrm{II}) 238.204$ & 13.11 & Ni(II) 221.648 & 14.27 \\
\hline V(II) 290.880 & 11.40 & $\mathrm{Fe}(\mathrm{II}) 239.562$ & 13.11 & $\mathrm{Cd}(\mathrm{II}) 226.502$ & 14.47 \\
\hline $\mathrm{Mg}(\mathrm{II}) 280.271$ & 12.07 & $\mathrm{Ca}(\mathrm{II}) 315.887$ & 13.16 & Cd(II) 214.440 & 14.77 \\
\hline $\operatorname{Mg}(\mathrm{II}) 279.553$ & 12.08 & $\mathrm{Ca}(\mathrm{II}) 317.933$ & 13.16 & $\mathrm{~Pb}$ (II) 220.353 & 14.79 \\
\hline $\operatorname{Mn}($ II) 260.568 & 12.19 & $\mathrm{Fe}(\mathrm{II}) 234.830$ & 13.19 & $\mathrm{Zn}$ (II) 206.200 & 15.40 \\
\hline $\operatorname{Mn}(\mathrm{II}) 259.372$ & 12.21 & $\mathrm{Fe}(\mathrm{II}) 234.349$ & 13.19 & $\mathrm{Zn}$ (II) 202.548 & 15.51 \\
\hline $\mathrm{Mn}$ (II) 257.610 & 12.25 & $\mathrm{Co}$ (II) 238.892 & 13.48 & Bi(II) 190.171 & 15.91 \\
\hline Cr(II) 284.325 & 12.65 & $\mathrm{Co}(\mathrm{II}) 236.380$ & 13.62 & $\mathrm{Cu}(\mathrm{II}) 224.700$ & 15.96 \\
\hline $\mathrm{Fe}(\mathrm{II}) 259.939$ & 12.67 & $\mathrm{Co}(\mathrm{II}) 228.616$ & 13.72 & $\mathrm{Cu}(\mathrm{II}) 213.597$ & 16.25 \\
\hline $\mathrm{Cr}$ (II) 283.563 & 12.69 & $\mathrm{Co}$ (II) 230.786 & 13.75 & $\operatorname{Mg}($ II $) 279.077$ & 16.51 \\
\hline $\mathrm{Cr}$ (II) 205.560 & 12.80 & $\mathrm{Co}$ (II) 231.160 & 13.81 & & \\
\hline $\mathrm{Mn}(\mathrm{II}) 294.920$ & 12.81 & $\mathrm{Ni}($ II) 231.604 & 14.03 & & \\
\hline
\end{tabular}

\section{Matrix effect under robust conditions}

The effect is notably reduced $(\mathrm{ME} \sim 5-10 \%$ ) for all lines with TEE $>8 \mathrm{eV}$ and for many lines $(\mathrm{ME} \leq 5 \%)$ with $\mathrm{TEE}<8 \mathrm{eV}$ under robust conditions (Fig. 3). Nevertheless, the ME is still high for some lines with TEE $<8 \mathrm{eV}$ (see lines marked in Fig. 3).

ME-TEE linear relationship remains statistically significant, although with lower strength, for $\mathrm{Al}(R=-0.30)$ and

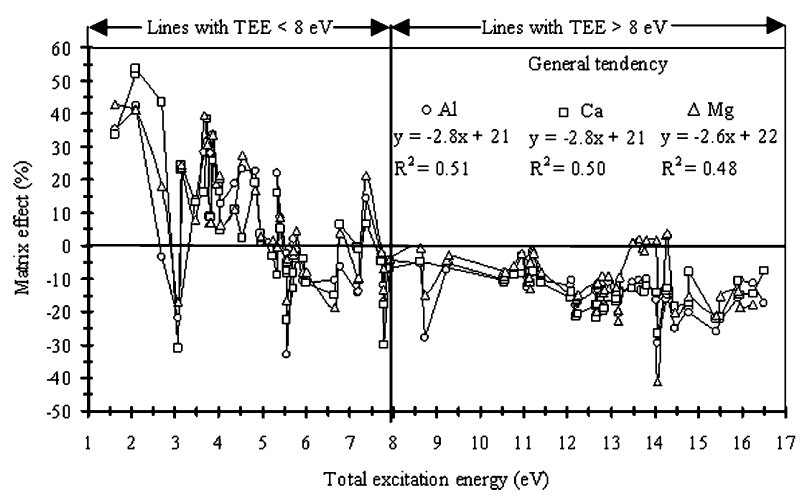

Fig. 1 Matrix effect as a function of the total excitation energy of the lines in the range from 1.62 to $16.51 \mathrm{eV}$ for $\mathrm{Al}(\bigcirc), \mathrm{Ca}(\square)$ and $\mathrm{Mg}$ $(\Delta)$ matrices under non-robust conditions (incident power $=0.80 \mathrm{~kW}$ and nebulizer argon flow rate $=1.201 \mathrm{~min}^{-1}$ ).
$\operatorname{Mg}(R=-0.38)$ matrices, while it is not significant $(R=-0.17)$ for $\mathrm{Ca}$ over the entire energy range. This correlation is lost when only lines with TEE $<8 \mathrm{eV}$ are considered. The dependence of ME on TEE is apparently flat for lines with TEE $>8 \mathrm{eV}$. However, a closer assessment reveals that the linear relationship between ME and TEE is not statistically significant only for the $\mathrm{Al}$ matrix $(R=0.017)$, while it is significant for $\mathrm{Ca}(R=-0.36)$ and $\mathrm{Mg}(R=-0.74)$ in the 8 to $16.51 \mathrm{eV}$ energy range. Furthermore, under robust conditions, ME tends to decrease linearly when $\operatorname{TEE}(\approx 13.5-16.5 \mathrm{eV})$ approximates the ionization energy of argon for $\mathrm{Al}, \mathrm{Ca}$ and $\mathrm{Mg}$, with statistically significant $R$ values of $0.53,0.54$ and 0.56 , respectively.

\section{Global explanation for the matrix effect}

As was shown, ME tends to decrease linearly with increasing TEE in the first part (TEE $<8 \mathrm{eV}$ ) and in the entire energy range 1.62-16.51 eV under non-robust conditions (Fig. 1). On the other hand, the logarithm of the population density $\left(n_{\mathrm{p}}\right)$ of the energy level " $p$ " decreases linearly with the excitation energy $\left(E_{p}\right)$ of this level for any element (neutral atom or ion) present in the plasma. ${ }^{1}$ Subsequently, it is our contention that the dependencies of ME vs. TEE, obtained in the present work, and $\ln \left(n_{\mathrm{p}}\right)$ vs. $E_{\mathrm{p}}$ are closely related. For example, the higher less populated atomic energy levels of $\mathrm{Al}, \mathrm{Ca}$ and $\mathrm{Mg}$ are near to $8 \mathrm{eV}$ because their first ionization energies are 5.98, 


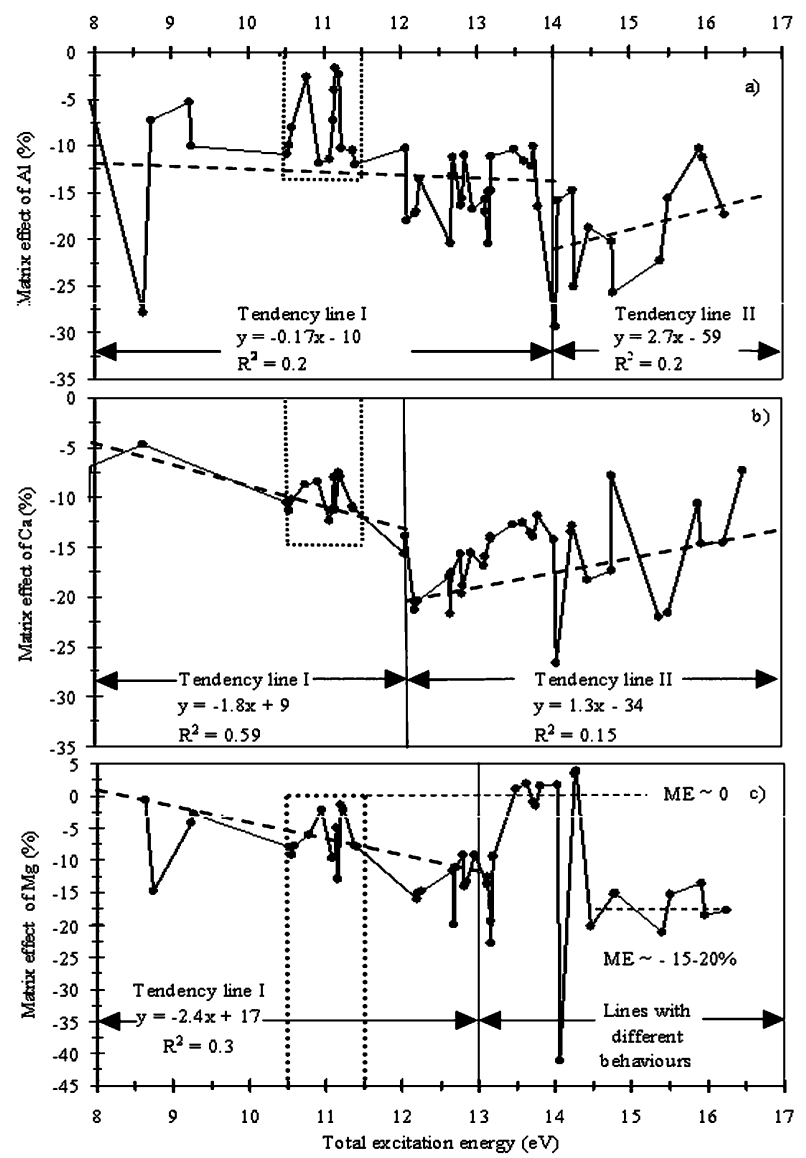

Fig. 2 Matrix effect as a function of the total excitation energy of the lines in the range from 8 to $16.51 \mathrm{eV}$ for $\mathrm{Al}$ (Fig. 2a), Ca (Fig. 2b) and $\mathrm{Mg}$ (Fig. 2c) matrices under non-robust conditions (incident power $=$ $0.8 \mathrm{~kW}$ and nebulizer argon flow rate $=1.201 \mathrm{~min}^{-1}$ ). Dotted rectangles refer to a specific behavior (see text for more details).

6.11 and $7.65 \mathrm{eV}$, respectively, and, precisely, the lower MEs are observed near $8 \mathrm{eV}$ in the $1.62-8 \mathrm{eV}$ range. Then, we consider, as a principal support for a global qualitative explanation of the ME mechanism in ICP, that the direct matrix-element interaction is given by the following general

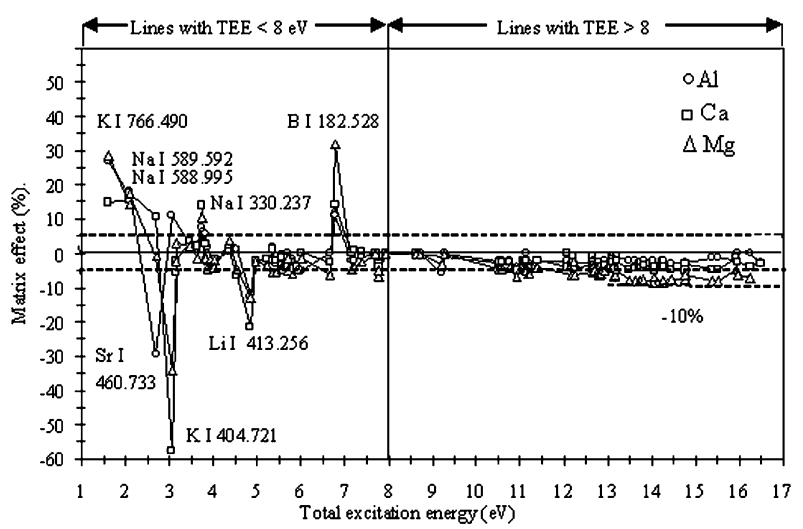

Fig. 3 Matrix effect as a function of the total excitation energy of the lines in the range from 1.62 to $16.51 \mathrm{eV}$ for $\mathrm{Al}(\bigcirc), \mathrm{Ca}(\square)$ and $\mathrm{Mg}$ $(\Delta)$ matrices under robust conditions (incident power $=1.50 \mathrm{~kW}$ and nebulizer argon flow rate $=0.601 \mathrm{~min}^{-1}$ ).

four-in-one eqn 2:

$$
M\left\{\begin{array}{c}
p^{\prime} \\
q^{\prime}
\end{array}\right\}+A\left\{\begin{array}{c}
q \\
p
\end{array}\right\} \leftrightarrow M\left\{\begin{array}{c}
q^{\prime} \\
p^{\prime}
\end{array}\right\}+A\left\{\begin{array}{c}
p \\
q
\end{array}\right\}+\Delta E
$$

where $M\left(p^{\prime}\right)$ and $M\left(q^{\prime}\right)$ are the matrix atoms or ions with the energy level $E_{p^{\prime}}$ and $E_{q^{\prime}}$ respectively, $A(p)$ and $A(q)$ are the analyte atoms or ions with the energy level $E_{p}$ and $E_{q}$, respectively, being $E_{p}<E_{q}$ and $E_{p^{\prime}}<E_{q^{\prime}}$ and $\Delta E$ is the difference between the final excitation energy of the system formed by both colliding specimens and the initial excitation energy of the system before the collision. The term $\Delta E$ allows that the total energy of the system is constant according to the Conservation Energy Law.

Reactions in eqn (2) can be split into four different ones: direct or inverse reactions taking the upper indexes $p^{\prime}+q \rightarrow q^{\prime}+p$, and two more taking the lower indexes $q^{\prime}+p \rightarrow p^{\prime}+q$.

\section{Matrix-analyte interaction for TEE $<8 \mathrm{eV}$}

The $n_{p}$ of the matrix is higher when the TEE of the line is lower. Therefore, we expect the reactions in eqn (2) to be favoured and, consequently, the ME would be greater for

Table 3 Some possible reactions described by the general eqn (2) corresponding to activation (ME $>0)$ and deactivation $(\mathrm{ME}<0)$ of atomic energy levels of the same analyte in the presence of the matrix ${ }^{a}$

\begin{tabular}{|c|c|c|c|c|c|c|c|c|c|c|c|c|c|c|}
\hline \multicolumn{7}{|l|}{ Reactants } & \multicolumn{8}{|l|}{ Products } \\
\hline Analyte line/nm & $\begin{array}{l}\text { ME } \\
(\%)\end{array}$ & $\begin{array}{l}\mathrm{TEE}_{1} / \\
\mathrm{eV}\end{array}$ & $S_{1}$ & Matrix & $\begin{array}{l}\mathrm{TEE}_{2 /} \\
\mathrm{eV}\end{array}$ & $S_{2}$ & Analyte line/nm & $\begin{array}{l}\text { ME } \\
(\%)\end{array}$ & $\begin{array}{l}\mathrm{TEE}_{3} / \\
\mathrm{eV}\end{array}$ & $S_{3}$ & Matrix & $\begin{array}{l}\mathrm{TEE}_{4} / \\
\mathrm{eV}\end{array}$ & $S_{4}$ & $\begin{array}{l}\Delta E / \\
\mathrm{eV}\end{array}$ \\
\hline $\mathrm{Bi}(\mathrm{I}) 223.061$ & -5 & 5.56 & $5 / 2$ & $\mathrm{Al}(\mathrm{I})$ & 3.14 & $1 / 2$ & $\mathrm{Bi}$ & 13 & 4.04 & $1 / 2$ & $\mathrm{Al}(\mathrm{I})$ & 5.48 & $5 / 2$ & 0.90 \\
\hline $\mathrm{Cu}(\mathrm{I}) 222.778$ & -33 & 5.57 & $1 / 2$ & $\mathrm{Al}(\mathrm{I})$ & 4.02 & $5 / 2$ & $\mathrm{Cu}(\mathrm{I}) 327.393$ & 28 & 3.79 & $1 / 2$ & $\mathrm{Al}(\mathrm{I})$ & 5.48 & $5 / 2$ & -0.23 \\
\hline $\mathrm{K}(\mathrm{I}) 404.721$ & -31 & 3.06 & $1 / 2$ & $\mathrm{Ca}(\mathrm{I})$ & 1.89 & 2 & $\mathrm{~K}(\mathrm{I}) 766.490$ & 34 & 1.62 & $3 / 2$ & $\mathrm{Ca}(\mathrm{I})$ & 1.62 & 1 & -0.27 \\
\hline $\mathrm{Cu}(\mathrm{I}) 222.778$ & -23 & 5.57 & $1 / 2$ & $\mathrm{Ca}(\mathrm{I})$ & 2.93 & 1 & $\mathrm{Cu}(\mathrm{I}) 327.393$ & 9 & 3.79 & $1 / 2$ & $\mathrm{Ca}(\mathrm{I})$ & 3.91 & 1 & 0.86 \\
\hline $\mathrm{Pb}(\mathrm{I}) 261.418$ & -13 & 5.71 & 2 & $\mathrm{Ca}(\mathrm{I})$ & 3.91 & 1 & $\mathrm{~Pb}(\mathrm{I}) 283.306$ & 11 & 4.37 & 1 & $\mathrm{Ca}(\mathrm{I})$ & 4.68 & 2 & 0.46 \\
\hline $\mathrm{Ni}(\mathrm{I}) 232.003$ & -9 & 5.34 & 5 & $\mathrm{Ca}(\mathrm{I})$ & 2.52 & 2 & $\mathrm{Ni}(\mathrm{I}) 341.476$ & 16 & 3.65 & 4 & $\mathrm{Ca}(\mathrm{I})$ & 4.74 & 3 & 1.13 \\
\hline $\mathrm{Bi}(\mathrm{I}) 223.061$ & -5 & 5.56 & $5 / 2$ & $\operatorname{Mg}(\mathrm{I})$ & 4.34 & 1 & $\mathrm{Bi}(\mathrm{I}) 306.766$ & 7 & 4.04 & $1 / 2$ & $\operatorname{Mg}(I)$ & 5.94 & 3 & -0.30 \\
\hline $\mathrm{Cu}(\mathrm{I}) 222.778$ & -16 & 5.57 & $1 / 2$ & $\operatorname{Mg}(I)$ & 2.71 & 2 & $\mathrm{Cu}(\mathrm{I}) 327.393$ & 7 & 3.79 & $1 / 2$ & $\operatorname{Mg}(\mathrm{I})$ & 5.93 & 2 & 1.07 \\
\hline B(I) 208.957 & -5 & 5.93 & $5 / 2$ & $\operatorname{Mg}(\mathrm{I})$ & 7.17 & 1 & $\mathrm{~B}(\mathrm{I}) \quad 182.528$ & 32 & 6.79 & $3 / 2$ & $\operatorname{Mg}(I)$ & 5.93 & 2 & -0.38 \\
\hline
\end{tabular}

${ }^{a} \mathrm{TEE}_{j}$ and $\mathrm{S}_{j}(j=1-4)$ are the excitation energy and the spin, respectively, of the involved energy levels. $\Delta E$ is the difference between the excitation energy of the product analyte atom and the excitation energy of the reactant matrix atom. ME was measured under non-robust conditions, except for the last reaction measured under robust conditions. 
Table 4 Some possible reactions described by the general eqn (2) corresponding to charge transfer between analyte and matrix energy levels ${ }^{a}$

\begin{tabular}{|c|c|c|c|c|c|c|c|c|c|c|c|c|c|c|}
\hline \multicolumn{7}{|l|}{ Reactants } & \multicolumn{8}{|l|}{$\underline{\text { Products }}$} \\
\hline Analyte line/nm & ME (\%) & $\mathrm{TEE}_{1} / \mathrm{eV}$ & $S_{1}$ & Matrix & $\mathrm{TEE}_{2} / \mathrm{eV}$ & $S_{2}$ & Analyte line/nm & $\operatorname{ME}(\%)$ & $\mathrm{TEE}_{3} / \mathrm{eV}$ & $S_{3}$ & Matrix & $\mathrm{TEE}_{4} / \mathrm{eV}$ & $S_{4}$ & $\Delta E / \mathrm{eV}$ \\
\hline Cd(II) 214.440 & -19 & 14.77 & $3 / 2$ & $\mathrm{Al}(\mathrm{I})$ & 5.48 & $5 / 2$ & $\mathrm{Cd}(\mathrm{I}) 361.051$ & 14 & 7.38 & $6 / 2$ & $\mathrm{Al}(\mathrm{II})$ & 13.40 & 1 & -1.37 \\
\hline $\mathrm{Pb}$ (II) 220.353 & -20 & 14.79 & $1 / 2$ & $\mathrm{Al}(\mathrm{I})$ & 4.02 & $3 / 2$ & $\mathrm{~Pb}$ (I) 283.306 & 19 & 4.37 & 1 & $\mathrm{Al}(\mathrm{II})$ & 13.40 & 1 & -1.39 \\
\hline $\mathrm{Cu}(\mathrm{II}) 224.700$ & -10 & 15.96 & 2 & $\mathrm{Al}(\mathrm{I})$ & 4.02 & $3 / 2$ & $\mathrm{Cu}(\mathrm{I}) 324.752$ & 28 & 3.82 & $3 / 2$ & $\mathrm{Al}(\mathrm{II})$ & 17.67 & 2 & 1.71 \\
\hline Bi (II) 190.171 & -16 & 15.91 & 1 & $\mathrm{Al}(\mathrm{I})$ & 4.02 & $3 / 2$ & Bi (I) 306.766 & 13 & 4.04 & $1 / 2$ & $\mathrm{Al}(\mathrm{II})$ & 17.67 & 2 & 1.76 \\
\hline $\mathrm{Ni}(\mathrm{II}) 231.604$ & -17 & 14.03 & $7 / 2$ & $\mathrm{Al}(\mathrm{I})$ & 4.02 & $3 / 2$ & $\mathrm{Ni}(\mathrm{I}) 341.476$ & 28 & 3.65 & 4 & $\mathrm{Al}(\mathrm{II})$ & 13.40 & 1 & -0.9 \\
\hline $\operatorname{Mg}(\mathrm{II}) 279.077$ & -17 & 16.51 & $3 / 2$ & $\mathrm{Al}(\mathrm{I})$ & 4.02 & $3 / 2$ & $\operatorname{Mg}(\mathrm{I}) 285.213$ & 22 & 5.35 & 1 & $\mathrm{Al}(\mathrm{II})$ & 17.40 & 2 & 0.89 \\
\hline $\mathrm{Pb}$ (II) 220.353 & -8 & 14.79 & $1 / 2$ & $\mathrm{Ca}(\mathrm{I})$ & 4.68 & 2 & $\mathrm{~Pb}(\mathrm{I}) 283.306$ & 11 & 4.37 & 1 & $\mathrm{Ca}(\mathrm{II})$ & 13.15 & $3 / 2$ & -1.64 \\
\hline $\mathrm{Ni}(\mathrm{II}) 231.604$ & -14 & 14.03 & $7 / 2$ & $\mathrm{Ca}(\mathrm{I})$ & 4.68 & 1 & $\mathrm{Ni}(\mathrm{I}) 341.476$ & 16 & 3.65 & 4 & $\mathrm{Ca}(\mathrm{II})$ & 12.58 & $1 / 2$ & -1.45 \\
\hline $\mathrm{Cu}(\mathrm{II}) 224.700$ & -18 & 15.96 & 2 & $\operatorname{Mg}(\mathrm{I})$ & 4.34 & 1 & $\mathrm{Cu}(\mathrm{I}) 327.393$ & 7 & 3.79 & $1 / 2$ & $\mathrm{Mg}(\mathrm{II})$ & 16.51 & $5 / 2$ & 0.55 \\
\hline
\end{tabular}

${ }^{a} \mathrm{TEE}_{j}$ and $\mathrm{S}_{j}(j=1-4)$ are the excitation energy and the spin, respectively, of the involved energy levels. $\Delta E$ is the difference between the excitation energy of the product matrix ion $(\mathrm{Al}, \mathrm{Ca}$ or $\mathrm{Mg}$ ) and the excitation energy of the reactant analyte ion. ME was measured under non-robust conditions.

decreasing TEE in the range $1.62-8 \mathrm{eV}$. This behaviour is experimentally corroborated by the tendency lines in Fig. 1.

Several specific matrix-analyte interactions following the general eqn (2) are shown in Table 3 for energy levels found in the available literature. ${ }^{26}$ It is worthy to note that if the considered analyte line $A(p)$ or $A(q)$ belongs to the reactant of the direct reaction in eqn (2), see reactant analyte lines with $\mathrm{ME}<0$ in Table 3, its emission intensity would decrease because the population of the corresponding level $E_{p}$ or $E_{q}$ decays. On the contrary, if the analyte line belongs to the product, see product analyte lines with $\mathrm{ME}>0$ in Table 3, its emission intensity would increase. Consequently, the enhancement and attenuation of different lines of the same analyte with $\mathrm{TEE}<8 \mathrm{eV}$ in the presence of the $\mathrm{Al}, \mathrm{Ca}$ and $\mathrm{Mg}$ matrices is explained. For the reactions proposed in Table 3 the sum of the spin of colliding specimens is equal before $\left(S_{1}+S_{2}\right)$ and after $\left(S_{3}+S_{4}\right)$ collision, and the difference of the excitation energy levels $(\Delta E)$ for which the energy transfer takes place is small $(-0.38<\Delta E<1.13 \mathrm{eV})$. Both conditions are the two principal characteristics of the energy transfer during inelastic collision between atoms. ${ }^{27}$

In this $1.62-8 \mathrm{eV}$ energy range, the interaction of the analyte and matrix species with argon (ions or atoms) is excluded because the difference between the excitation energy of argon and of the other elements is larger than the $\Delta E \sim 2 \mathrm{eV}$ experimentally observed for charge transfer and proposed for Penning ionization in ICP. ${ }^{17}$

\section{Matrix-analyte interaction for TEE $>8 \mathrm{eV}$}

The ME in the ionic lines zone would be expected to behave similarly to the ME in the atomic lines zone, as expressed by eqn (2). However, the Ar energy levels ( 11-16 eV) should have an influence on the matrix-analyte interaction. The $\mathrm{Ar}$ energy levels provoke charge transfer and, possibly, Penning reactions in analytes. Both processes are excitation mechanisms stronger than the possible matrix-analyte interactions, because the population of Ar is always significantly larger than that of the matrix. The amount of energy delivered from Ar to analytes is smaller when the matrix is present, giving a negative ME in this ionic zone (Fig. 1). As it occurs for the matrix, the $\ln \left(n_{p}\right)$ of the atomic energy level of the $\mathrm{Ar}$ also decreases linearly with the energy of the level. However, in this case, argon $n_{p}$ is higher for energies near $11 \mathrm{eV}$ and therefore the analyte exciting process by $\mathrm{Ar}$ is favoured at these low energies. This is, probably, the reason why the disturbing effect of the matrix is not only depressive but also less severe for lower $(\sim 8-11 \mathrm{eV})$ analyte line energies. On the contrary, neutral argon $n_{p}$ decreases for energies higher than $11 \mathrm{eV}$. Then, the analyte exciting process by Ar is disfavoured and, therefore, the action of the matrix by eqn (2) is more relevant. This fact would explain the increase of the depressive effect, as a general tendency, with the TEE in the $8-16.51 \mathrm{eV}$ range (Fig. 1). The departures of this depressive effect from the general tendency line can be explained as a consequence of the position of the analyte as reactant (negative departure) or product (positive departure) in eqn (2).

Possible charge transference matrix-analyte reactions by eqn (2) are shown in Table 4. The depopulation and population, respectively, of their upper energy levels can explain the attenuation $(\mathrm{ME}<0)$ of the reactants ionic lines and the enhancement $(\mathrm{ME}>0)$ of the products atomic lines. The Wigner's Law and the resonance energy effect are also possible for these reactions.

Finally, the ME over five of the lines with TEE 10.5-11.5 $\mathrm{eV}$ (see lines marked in Fig. 4) is significantly reduced. This attenuation of the ME can be explained by the more efficient excitation of those lines through the Penning ionization mechanism induced by the $11.548 \mathrm{eV}$ metastable $\left(\mathrm{Ar}^{\mathrm{m}}\right)$ and the $11.624 \mathrm{eV}$ radiative $\left(\mathrm{Ar}^{\mathrm{r}}\right)$ argon energy levels following the first

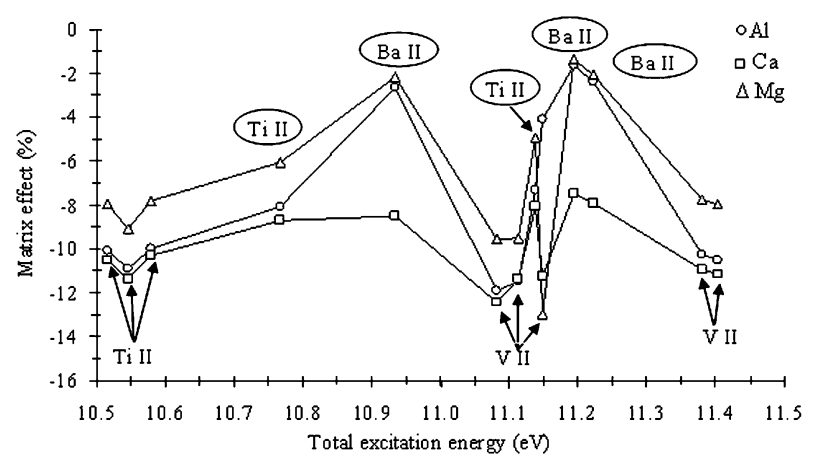

Fig. 4 Matrix effect as a function of the total excitation energy of the lines in the range from 10.5 to $11.5 \mathrm{eV}$ for $\mathrm{Al}(\bigcirc), \mathrm{Ca}(\square)$ and $\mathrm{Mg}(\Delta)$ matrices under non-robust conditions (incident power $=0.8 \mathrm{~kW}$ and nebulizer argon flow rate $=1.201 \mathrm{~min}^{-1}$ ). 


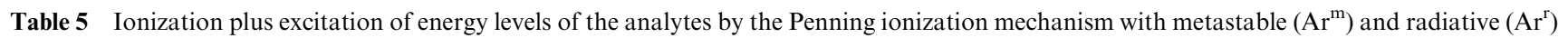
argon energy levels ${ }^{a}$

\begin{tabular}{|c|c|c|c|c|c|c|c|c|c|c|c|c|c|}
\hline \multicolumn{6}{|l|}{ Reactants } & \multicolumn{8}{|l|}{$\underline{\text { Products }}$} \\
\hline Analyte line/nm & $\mathrm{TEE}_{1} / \mathrm{eV}$ & $S_{1}$ & ExcitingAr & $\mathrm{TEE}_{2} / \mathrm{eV}$ & $S_{2}$ & Analyte line/nm & $\mathrm{TEE}_{3} / \mathrm{eV}$ & $S_{3}$ & Deactivated Ar & $\mathrm{TEE}_{4} / \mathrm{eV}$ & $S_{4}$ & $S_{e}$ & $\Delta E / \mathrm{eV}$ \\
\hline $\mathrm{Ba}(\mathrm{I}) 553.548$ & 2.24 & 1 & $\mathrm{Ar}^{\mathrm{m}}$ & 11.548 & 2 & $\mathrm{Ba}(\mathrm{II}) 413.065$ & 10.93 & $5 / 2$ & $\mathrm{Ar}_{0}$ & 0 & 0 & $1 / 2$ & -0.62 \\
\hline $\mathrm{Ba}(\mathrm{I}) 553.548$ & 2.24 & 1 & $\mathrm{Ar}^{\mathrm{m}}$ & 11.548 & 2 & $\mathrm{Ba}$ (II) 230.425 & 11.19 & $5 / 2$ & $\mathrm{Ar}_{0}$ & 0 & 0 & $1 / 2$ & -0.36 \\
\hline $\mathrm{Ba}(\mathrm{I}) 232.536$ & 1.67 & 2 & $\operatorname{Ar}^{\mathrm{m}}$ & 11.548 & 2 & $\mathrm{Ba}(\mathrm{II}) 233.527$ & 11.22 & $7 / 2$ & $\mathrm{Ar}_{0}$ & 0 & 0 & $1 / 2$ & -0.33 \\
\hline $\mathrm{Ti}(\mathrm{I}) 521.038$ & 2.43 & 4 & $\operatorname{Ar}^{\mathrm{r}}$ & 11.624 & 1 & $\mathrm{Ti}(\mathrm{II}) 334.903$ & 11.14 & $9 / 2$ & $\mathrm{Ar}_{0}$ & 0 & 0 & $1 / 2$ & -0.41 \\
\hline $\operatorname{Ti}(\mathrm{I}) 501.419$ & 2.47 & 1 & $\operatorname{Ar}^{\mathrm{r}}$ & 11.624 & 1 & Ti(II) 368.519 & 10.77 & $3 / 2$ & $\mathrm{Ar}_{0}$ & 0 & 0 & $1 / 2$ & -0.85 \\
\hline $\operatorname{Ti}(\mathrm{I}) 506.465$ & 2.49 & 3 & $\mathrm{Ar}^{\mathrm{r}}$ & 11.624 & 1 & $\mathrm{Ti}$ (II) 337.279 & 10.52 & $7 / 2$ & $\mathrm{Ar}_{0}$ & 0 & 0 & $1 / 2$ & -1.10 \\
\hline $\mathrm{Ti}(\mathrm{I}) 521.038$ & 2.43 & 4 & $\mathrm{Ar}^{\mathrm{r}}$ & 11.624 & 1 & $\mathrm{Ti}$ (II) 336.121 & 10.55 & $9 / 2$ & $\mathrm{Ar}_{0}$ & 0 & 0 & $1 / 2$ & -1.07 \\
\hline $\operatorname{Ti}(\mathrm{I}) 521.038$ & 2.43 & 4 & $\mathrm{Ar}^{\mathrm{r}}$ & 11.624 & 1 & $\mathrm{Ti}(\mathrm{II}) 334.903$ & 11.14 & $9 / 2$ & $\mathrm{Ar}_{0}$ & 0 & 0 & $1 / 2$ & -0.48 \\
\hline V(I) 439.522 & 3.01 & $5 / 2$ & $\mathrm{Ar}^{\mathrm{m}}$ & 11.548 & 2 & V(II) 311.071 & 11.08 & 4 & $\mathrm{Ar}_{0}$ & 0 & 0 & $1 / 2$ & -0.47 \\
\hline V(I) 438.998 & 3.10 & $7 / 2$ & $\mathrm{Ar}^{\mathrm{m}}$ & 11.548 & 2 & V(II) 310.230 & 11.11 & 5 & $\mathrm{Ar}_{0}$ & 0 & 0 & $1 / 2$ & -0.44 \\
\hline V(I) 438.471 & 3.11 & $9 / 2$ & $\mathrm{Ar}^{\mathrm{m}}$ & 11.548 & 2 & V(II) 309.310 & 11.15 & 6 & $\mathrm{Ar}_{0}$ & 0 & 0 & $1 / 2$ & -0.40 \\
\hline V(I) 438.998 & 3.10 & $7 / 2$ & $\mathrm{Ar}^{\mathrm{m}}$ & 11.548 & 2 & V(II) 292.402 & 11.38 & 5 & $\mathrm{Ar}_{0}$ & 0 & 0 & $1 / 2$ & -0.17 \\
\hline V(I) 439.522 & 3.01 & $5 / 2$ & $\operatorname{Ar}^{\mathrm{m}}$ & 11.548 & 2 & V(II) 290.880 & 11.40 & 4 & $\mathrm{Ar}_{0}$ & 0 & 0 & $1 / 2$ & -0.15 \\
\hline
\end{tabular}

five reactions in Table 5. For all the reactions proposed, the total spin of the system $\left(S_{1}+S_{2}=S_{3}+S_{4}+S_{e}\right)$ is kept constant and $\Delta E$ is small ( $<1 \mathrm{eV}$ in absolute value), according to Wigner's Law and the resonance energy effect, respectively. ${ }^{27}$ Analogous Penning reactions are also possible for the remaining analyte lines (see the last eight reactions in Table 5), which suggest the need for more specific experiments to elucidate the behavior of these eight lines.

\section{Conclusions}

A global qualitative explanation of the matrix effect mechanism in ICP-AES, based on the energy transfer during inelastic collisions between analyte and matrix specimens (atoms or ions) is proposed. Several matrix-analyte reactions were provided. Some of them explained the simultaneous enhancement and attenuation of intensity of atomic lines with TEE $<8 \mathrm{~V}$ belong to the same analyte. Other reactions link the attenuation of ionic and the enhancement of atomic lines of the same analyte by charge transference between analyte and matrix.

The characteristic ME due to $\mathrm{Al}$ and $\mathrm{Ca}$ in the $15 \mathrm{eV}$-energy zone has corroborated the relevant role of the charge transference by $\mathrm{Ar}^{+}$for lines with TEE $\approx 15.76 \mathrm{eV}$. In the presence of $\mathrm{Mg}$, other possible matrix-analyte interactions may reduce the efficiency of this mechanism.

The relative reduction of the ME observed for the studied matrices on five lines with TEE in the 10.5-11.5 eV range can be considered as experimental evidence of the Penning ionization and excitation mechanism in axial view mode ICP-AES.

\section{Acknowledgements}

This work has been partially supported by the National Program of Science and Technological Innovations of Cuba "New and Advanced Materials" through the Project B7, the Higher Education Ministry of Cuba through the 2005 Convocation 6.144 Project, the Cooperation Program between Complutense University of Madrid and University of Havana and the SCH-University Complutense of Madrid Distinguished Visitors Programme of the 2005 convocation. The authors wish to thank Dr Oscar Ruano from the National Center for Metallurgic Research, CSIC, Spain, for useful comments.

\section{References}

1 Inductively Coupled Plasmas in Analytical Atomic Spectrometry, ed. A. Montaser and D. W. Golightly, VCH Publishers, Inc., New York, 1987, ch. 16.

2 J. M. Mermet, J. Anal. At. Spectrom., 2005, $20,11$.

3 M. W. Blades and G. Horlick, Spectrochim. Acta, Part B, 1981, 36, 881.

4 I. B. Brenner and A. T. Zander, Spectrochim. Acta, Part B, 2000, $\mathbf{5 5}, 1195$.

5 J. L. Todolí, L. Gras, V. Hernandis and J. Mora, J. Anal. At. Spectrom., 2002, 17, 142.

6 J. M. Mermet, Anal. Chim. Acta, 1991, 250, 85.

7 G. C.-Y. Chan and W.-T. Chan, Spectrochim. Acta, Part B, 2003, 58, 1301.

8 G. C.-Y. Chan and G. M. Hieftje, Spectrochim. Acta, Part B, 2004, 59, 163.

9 Y. Mosqueda, M. Pomares, E. L. Pérez-Cappe, A. Miranda, J. C. Fariñas and M. T. Larrea, Anal. Bioanal. Chem., 2006, 386, 1855.

10 M. Iglesias, T. Vaculovic, J. Studynkova, E. Poussel and J. M. Mermet, Spectrochim. Acta, Part B, 2004, 59, 1841.

11 I. B. Brenner, A. Zander, M. Cole and A. Wiseman, J. Anal. At. Spectrom., 1997, 12, 897.

12 I. B. Brenner, M. Zischa, B. Maichin and G. Knapp, J. Anal. At. Spectrom., 1998, 13, 1257.

13 I. B. Brenner, A. Le Marchand, C. Daraed and L. Chauvet, Microchem. J., 1999, 63, 344.

14 M. Stepan, P. Musil, E. Poussel and J. M. Mermet, Spectrochim. Acta, Part B, 2001, 56, 443.

15 Y.-C. Sun, S.-H. Wu and C.-C. Lee, J. Anal. At. Spectrom., 2003, 18, 1163.

16 C. Dubuisson, E. Poussel and J. M. Mermet, J. Anal. At. Spectrom., 1998, 13, 1265.

17 Y. Chan and G. M. Hieftje, Spectrochim. Acta, Part B, 2006, 61, 642.

18 M. Villanueva, M. Catasús, E. D. Salin and M. Pomares, J. Anal. At. Spectrom., 2000, 7, 877.

19 M. Thompson and M. H. Ramsey, Analyst, 1985, 110, 1413. 
20 M. W. Blades and G. Horlick, Spectrochim. Acta, Part B, 1981, 36, 881.

21 J. Davies and R. D. Snook, J. Anal. At. Spectrom., 1986, 1, 325.

22 A. S. Al-Ammar and R. M. Barnes, Spectrochim. Acta, Part B, 1999, 54, 1063.

23 T. C. Krehbiel, Correlation Coefficient Rule of Thumb, Miami University, http://kelley.iupui.edu/dsjie/Tips/krehbiel.htm.

24 P. B. Farnsworth, A. Woolley, N. Omenetto and O. Matveev, Spectrochim. Acta, Part B, 1999, 54, 2143.
25 G. C.-Y. Chan and G. M. Hieftje, Spectrochim. Acta, Part B, 2004, 59, 1007.

26 J. E. Sansonetti and W. C. Martin, NIST Handbook of Basic Atomic Spectroscopic Data, National Institute of Standards and Technology, http://physics.nist.gov/PhysRefData/Handbook/ index.html.

27 H. S. W. Massey, E. H. S Burhop and H. B. Gilbody, Electronic and Ionic Impact Phenomena, Clarendon Press, Oxford, 2nd edn, 1971, vol. 3, ch. 18, pp. 1651-1931. 